\title{
An Investigation of Organic and Inorganic Mercury Exposure and Blood Pressure in a Small-Scale Gold Mining Community in Ghana
}

\author{
Mozhgon Rajaee ${ }^{1}$, Brisa N. Sánchez ${ }^{2}$, Elisha P. Renne ${ }^{3,4}$ and Niladri Basu $^{1,5, *}$
}

1 Department of Environmental Health Sciences, University of Michigan School of Public Health, 1415 Washington Heights, Ann Arbor, MI 48109, USA; E-Mail: mrajae@umich.edu

2 Department of Biostatistics, University of Michigan School of Public Health, 1415 Washington Heights, Ann Arbor, MI 48109, USA; E-Mail: brisa@umich.edu

3 Department of Anthropology, University of Michigan, 101 West Hall, Ann Arbor, MI 48109, USA; E-Mail: erenne@umich.edu

4 Department of Afroamerican and African Studies, University of Michigan, 4700 Haven Hall, Ann Arbor, MI 48109, USA

5 Faculty of Agricultural and Environmental Sciences, McGill University, 21, 111 Lakeshore Rd., Ste. Anne de Bellevue, QC H9X 3V9, Canada

* Author to whom correspondence should be addressed; E-Mail: niladri.basu@ @mcgill.ca; Tel: +1-514-398-8642.

Academic Editors: Susan Keane and Paleah Black Moher

Received: 26 June 2015 / Accepted: 17 August 2015 / Published: 21 August 2015

\begin{abstract}
There is increasing concern about the cardiovascular effects of mercury $(\mathrm{Hg})$ exposure, and that organic methylmercury and inorganic $\mathrm{Hg}^{2+}$ may affect the cardiovascular system and blood pressure differentially. In small-scale gold mining communities where inorganic, elemental $\mathrm{Hg}$ exposures are high, little is known about the effects of $\mathrm{Hg}$ on blood pressure. In 2011, we assessed the relationship between $\mathrm{Hg}$ exposure and blood pressure (BP) in a cross-sectional study of adults from a small-scale gold mining community, Kejetia, and subsistence farming community, Gorogo, in Ghana's Upper East Region. Participants' resting heart rate and BP were measured, and hair and urine samples were provided to serve as biomarkers of organic and inorganic $\mathrm{Hg}$ exposure, respectively. Participants included 70 miners and 26 non-miners from Kejetia and 75 non-miners from Gorogo. Total specific gravity-adjusted urinary and hair $\mathrm{Hg}$ was higher among Kejetia
\end{abstract}


miners than Kejetia non-miners and Gorogo participants (median urinary $\mathrm{Hg}: 5.17,1.18$, and $0.154 \mu \mathrm{g} / \mathrm{L}$, respectively; hair $\mathrm{Hg}$ : 0.945, 0.419, and $0.181 \mu \mathrm{g} / \mathrm{g}$, respectively). Hypertension was prevalent in $17.7 \%$ of Kejetia and $21.3 \%$ of Gorogo participants. Urinary and hair $\mathrm{Hg}$ were not significantly associated with systolic or diastolic BP for Kejetia or Gorogo participants while adjusting for sex, age, and smoking status. Although our results follow trends seen in other studies, the associations were not of statistical significance. Given the unique study population and high exposures to inorganic $\mathrm{Hg}$, the work contained here will help increase our understanding of the cardiovascular effects of $\mathrm{Hg}$.

Keywords: mercury; blood pressure; Ghana; artisanal and small-scale gold mining; ASGM

\section{Introduction}

Mercury is an established pollutant of global concern given the body of evidence concerning its neurological impacts [1,2]. In recent years there has been increasing concern over the impact of mercury $(\mathrm{Hg}$ ) on the cardiovascular system, though studies have been limited with variable results. $\mathrm{Hg}$, particularly organic $\mathrm{Hg}$, has been associated with increases in carotid intima-media thickness and obstruction, coronary heart disease, myocardial infarctions, cerebrovascular accidents, cardiac arrhythmias, heart rate variability, atherosclerosis, carotid artery disease, and renal dysfunction [2,3].

The mechanisms through which $\mathrm{Hg}$ affects blood pressure (BP) are not well defined, but point toward oxidative stress as being key [4,5]. Increases in oxidative stress from lipid peroxidation and reduced antioxidant capacity can promote endothelial and renal dysfunction, which can increase the risk of hypertension and atherosclerosis, and result in the elevation of pulse pressure [3,6-9]. While the majority of the research shows $\mathrm{Hg}$ to increase oxidative stress, endothelial dysfunction, and subsequently BP, Rhee and Choi [10] found that inorganic $\mathrm{Hg}$ can cause a decrease in renal blood flow while renal activity remains constant, as inorganic $\mathrm{Hg}$ may inhibit sodium and chloride reabsorption in the kidneys [11].

Most research concerning the cardiovascular impact of $\mathrm{Hg}$ has focused on organic $\mathrm{Hg}$, or methylmercury ( $\mathrm{MeHg}$ ), exposure and $\mathrm{BP} . \mathrm{MeHg}$ is generally measured in hair and reflects the blood $\mathrm{Hg}$ concentrations at the time of hair growth (an average of one centimeter per month) $[1,12]$. This form of $\mathrm{Hg}$ exposure mainly comes from seafood consumption, and exposures have generally been associated with increases in systolic BP (SBP) and diastolic BP (DBP). For example, MeHg-associated increases in SBP have been found in studies of male whalers from the Faroe Islands [13], communities along the Brazilian Amazon [14], and adult Inuit from Nunavik, Canada [15]. Exposure-related increases in DBP have also been reported in the aforementioned study of Farose whalers as well as a study of U.S. Michigan dentists $[13,16]$. These results are summarized in Table 1.

Unlike $\mathrm{MeHg}$, much less is known about the cardiovascular effects of inorganic $\mathrm{Hg}$ exposure. Elemental $\mathrm{Hg}$, a type of inorganic $\mathrm{Hg}$, can be measured in urine to assess medium-term exposure, as it has a half-life of about 56-58 days in the kidneys [1,17]. Some animal studies have shown that elemental $\mathrm{Hg}$ exposure reduces heart rate, lowers BP, and causes arrhythmias [10,18,19]. There is some limited evidence from human population studies in support of the animal work. Epidemiologic 
studies have observed significant decreases in SBP with urinary $\mathrm{Hg}$ [16,20,21]. A study of U.S. adults with background exposure to elemental $\mathrm{Hg}$ observed significant decreases in SBP [20]. U.S. Michigan dentists with slightly elevated elemental $\mathrm{Hg}$ exposures had significant decreases in SBP with increasing urinary $\mathrm{Hg}$ [16]. Despite this research, there exists some contradictory evidence. A study of U.S. young adults with dental amalgams, which was ascribed to reflect long-term $\mathrm{Hg}$ exposure, were found to have significantly higher SBP and DBP than non-amalgam participants [21]. The study also observed a significant negative correlation of SBP and DBP with urinary $\mathrm{Hg}$, a reflection of shorter-term exposure [21]. This amalgam group also had a significantly lower pulse than the non-amalgam participants, but saw a positive correlation between pulse and urinary $\mathrm{Hg}$ [21]. Male Slovenian $\mathrm{Hg}$ miners had significantly higher SBP and DBP than non-miner controls, and a positive correlation of SBP and DBP with mean past urinary $\mathrm{Hg}$ exposures [22]. The results of these studies are summarized in Table 1. Population surveys have indicated widespread exposure to inorganic forms of $\mathrm{Hg}$ in many countries (e.g., USA, Canada) [23,24], thus supporting the need for more work on the potential effects of inorganic $\mathrm{Hg}$ on the cardiovascular system.

Table 1. Summary of $\mathrm{Hg}$ biomarkers (blood, hair, urine) and associations (indicated as either positive or negative) between $\mathrm{Hg}$ biomarkers and SBP and DBP from other studies.

\begin{tabular}{|c|c|c|c|c|c|c|}
\hline Study & $n$ & Mean Hg & Population & SBP & DBP & Media \\
\hline Park et al. (2013) [20] & 6607 & $1.03^{\mathrm{a}}$ & US NHANES adults & - & + & Blood \\
\hline Valera et al. (2009) [15] & 732 & $879^{a}$ & Canadian Nunavik Inuit adults & + & + & Blood \\
\hline Goodrich et al. (2012) [16] & 262 & 0.45 & US Michigan dentists (adults) & + & + & Hair \\
\hline Dorea et al. (2005) [25] & 296 & $3.4,12.8^{\mathrm{c}}$ & $\begin{array}{l}4 \text { Brazilian historic gold mining } \\
\text { communities (adults) }\end{array}$ & + & + & Hair \\
\hline Choi et al. (2009) [13] & 42 & $7.31^{a}$ & Farose whaling male adults & + & + & Hair \\
\hline Fillion et al. (2006) [14] & 251 & 17.8 & 6 Brazilian communities (adults) & + & + & Hair \\
\hline Park et al. (2013) [20] & 2201 & $0.51^{\mathrm{a}}$ & US NHANES adults & - & + & Urine \\
\hline Goodrich et al. (2012) [16] & 262 & 0.94 & US Michigan dentists (adults) & - & - & Urine \\
\hline Siblerud (1990) [21] & 101 & $1.23,3.7^{\mathrm{d}}$ & US Utahan young adults & - & - & Urine \\
\hline Kobal et al. (2004) [22] & 112 & $69.3^{\mathrm{b}}$ & $\begin{array}{l}\text { Slovenian male } \mathrm{Hg} \text { miners } \\
\qquad(\mathrm{n}=54) \& \text { control }\end{array}$ & + & + & Urine \\
\hline
\end{tabular}

${ }^{\mathrm{a}}$ Geometric mean; ${ }^{\mathrm{b}}$ Mean annual past urinary $\mathrm{Hg}$ exposure; ${ }^{\mathrm{c}}$ Dorea et al. (2005): 3.4 is the mean for three communities; 12.8 is the mean for one community; d Siblerud (1990): 1.23 is the mean for nonamalgam group $(\mathrm{n}=51) ; 3.70$ is the mean for amalgam group $(\mathrm{n}=50)$.

Exposures to inorganic $\mathrm{Hg}$ are perhaps highest amongst members of artisanal and small-scale gold mining (ASGM) communities. This form of mining utilizes elemental $\mathrm{Hg}$ to bind gold, and has recently been suggested to be the largest overall contributor to global anthropogenic $\mathrm{Hg}$ in the atmosphere [26]. ASGM communities are unique in their potentially high exposure to elemental $\mathrm{Hg}$ used in the mining process [27]. Biological markers of elemental and organic $\mathrm{Hg}$ concentrations are predominantly measured through urine and hair, respectively $[1,28,29]$.

Hypertension is a growing problem in Ghana, like other developing countries, and was the fifth largest cause of outpatient morbidity in 2008 [30]. An estimated 3.5 million Ghanaians over 15 years of age have hypertension [30]. A 1973 study reviewing rural Ghanaian villages found the prevalence 
of hypertension (defined as DBP > $95 \mathrm{mmHg}$ ) to be $2.5 \%$ for participants aged 16-54 years, and $4.5 \%$ for all participants over 16 years [31]. A 2010 review of hypertension studies in Ghana found that the prevalence of hypertension ranged from $19 \%$ to $48 \%$; and estimated hypertension prevalence at $20 \%$ in rural areas and $25 \%$ in urban areas [30]. In addition to the problem of rising hypertension, less than one-third of hypertensive adults from Ghanaian studies in 2005 were even aware that they had hypertension [30].

There have been no studies to-date exploring $\mathrm{Hg}$ exposures in small-scale gold miners in relation to cardiovascular health. This unknown relationship with high $\mathrm{Hg}$ exposures and the growing problem of hypertension may pose a problem for small-scale gold miners in Ghana and across the world. This study seeks to elucidate the relationship of hair and urinary $\mathrm{Hg}$ with cardiovascular health through assessing BP and heart rate. It examines a unique population with elevated exposures to further determine the true impacts of inorganic $\mathrm{Hg}$ on BP. Based on previous research, we hypothesized that hair $\mathrm{Hg}$ would be associated with an increase in systolic and diastolic BP and urinary $\mathrm{Hg}$ would be associated with a decrease in systolic BP [13-16,20-22].

\section{Materials and Methods}

\subsection{Study Populations}

Two study populations were identified in the Upper East Region of Ghana: Kejetia, a small-scale gold mining community [32], and Gorogo, a subsistence farming community. Participants were recruited by household in a cross sectional study from May through July 2011. Members of each household were defined as those who eat from the same "pot", with up to four adults interviewed per household. Institutional Review Board (IRB) approval was obtained through the University of Michigan (HUM00028444). Permission to work with the community was given by both communities' traditional chief and the Assemblyperson representing the community in Gorogo.

A household head was interviewed on household characteristics including demographics, water use, and cooking fuel. The household head and up to three other adult (18 years or older) household members were interviewed on their occupational and medical histories. Questions were adapted from the Ghana Demographic and Health Survey [33], and the American Thoracic Society's Epidemiology Standardization Project [34].

In Kejetia, all households were divided into 20 clusters. In each cluster, households were randomly assigned a number, and two to three households were sampled within each cluster by drawing a number at random from a bag. Only one household from one to three clusters was interviewed per day. Due to the large geographic dispersion of the Gorogo community, households were selected through convenience sampling. A bottle was spun at a community landmark initially and the household in the bottle's direction was selected [35]. Spinning a bottle at the preceding participating household identified subsequent households. One Gorogo participant was excluded for being a current miner.

\subsection{Mercury Exposure Assessment}

Urine was collected to assess elemental $\mathrm{Hg}$ exposure and hair to assess $\mathrm{MeHg}$ exposure [1]. Spot urine samples $(5-15 \mathrm{~mL})$ were collected by participants at the time of the interview, stored at room 
temperature in Ghana, and frozen until analysis in the U.S. Hair was cut as close to the scalp as possible from the occipital region of the head and placed on a sticky-note and stored in a plastic bag until analysis. Only the $2 \mathrm{~cm}$ closest to the scalp was used for analysis [32].

Total Hg was measured using a Direct Mercury Analyzer-80 (DMA-80; Milestone, Inc., Shelton, CT, USA), following U.S. EPA Method 7473 [36]. Urine (500 $\mu$ L) was vortexed and hair washed with acetone and deionized water before analysis. Certified reference materials (CRMs; urine: QMEQAS, Institut National de Santa Publique Quebec; hair: NIES Japan; dogfish liver: DOLT-4, National Research Council Canada) were analyzed approximately every ten samples, blanks every five samples, and sample replicates at least every nine samples. The detection limit, recovery rates of CRMs, and within-day variations for urine and hair samples are provided in Rajaee i.e. [37].

Specific gravity (SG) was measured using a pocket refractometer (PAL-10S, Atago U.S.A., Inc., Tokyo, Japan) to adjust urine samples by urinary dilution using the mean urinary specific gravity in Kejetia and Gorogo (1.016) [38,39]. The equation is as follows, where $p$ refers to a participant's personal urinary $\mathrm{Hg}$ and urinary SG values:

$$
S G \text { adjusted urinary } H g_{p}=\frac{(\text { Avg.urinary } S G-1)}{\left(\text { Urinary } S G_{p}-1\right)} \times \text { Urinary } H g_{p}
$$

Statistical analyses were performed with specific gravity-adjusted and non-adjusted urinary $\mathrm{Hg}$.

\subsection{Blood Pressure and Pulse Assessment}

Participants had their systolic and diastolic BP and heart rate (HR), or pulse, measured three times according to American Heart Association standards (AHA) [40,41] using a manual sphygmomanometer (Omron HEM-432C; Omron Healthcare, Inc., Lake Forest, IL) about $2 \mathrm{~cm}$ above the right elbow, above the brachial artery as we have previously detailed [16]. Participants were asked to sit on a chair or stool (with back support when possible) for the duration of the occupational survey, to allow for participants to rest for at least 10 minutes before measurements were taken. Three measurements were averaged for each participant's BP and pulse. Variability of each individual's replicates averaged 4.7\% (SBP), 5.4\% (DBP), and 3.5\% (pulse).

BP values were classified by AHA standards for hypertensive status, with apparent hypertension defined as $\mathrm{SBP} \geq 140 \mathrm{mmHg}$ or DBP $\geq 90 \mathrm{mmHg}$ [40,41]. Pulse pressure (PP) was calculated from the difference between the systolic and diastolic BP. Mean arterial pressure (MAP) was calculated from $\mathrm{DBP}+(1 / 3)^{*}$ pulse pressure [42]. One $(\mathrm{n}=1)$ male participant from Kejetia was excluded from analyses for taking anti-hypertensive medication at the time of the survey (his urinary $\mathrm{Hg}$ was 167.2 $\mu \mathrm{g} / \mathrm{L}$ unadjusted and $116.3 \mu \mathrm{g} / \mathrm{L}$ adjusted for specific gravity). Participants with emergency high BP (SBP $\geq 180$ or DBP $\geq 110 \mathrm{mmHg}$; three in Kejetia and one in Gorogo) were counseled at the time of the interview to seek advice from a medical professional.

\subsection{BMI and Smoking}

Each participant's body mass index (BMI) was calculated by dividing the participant's weight (kg) by his/her squared height (m), to assess obesity. Participant's smoking history was assessed to classify participants as current, ex, and never smokers. Participants were classified as never-smokers if they 
had smoked less than 100 cigarettes in their lifetime. Smoking pack-years reflect the average packs (20 cigarettes per pack) of cigarettes smoked per day for the duration of a person's smoking years.

\subsection{Statistical Analyses}

Data were analyzed using SPSS Statistical Software (v.22; IBM, Chicago, IL, USA). Urinary and hair $\mathrm{Hg}$ biomarkers that were not normally distributed were analyzed using Spearman correlations for bivariate analyses. Multivariable linear regressions were used to determine factors that influenced BP measures (SBP, DBP, pulse pressure, mean arterial pressure, and pulse). Sex, age, and smoking status (current and ex) were all controlled for in regression models, in addition to the exposure variables of interest: hair and urinary $\mathrm{Hg}$ (unadjusted and specific gravity-adjusted). Multivariable analyses were performed for the community and for miners in Kejetia. Analyses were stratified by community to better assess the impact of $\mathrm{Hg}$ exposures on $\mathrm{BP}$, since $\mathrm{Hg}$ exposure was confounded by community. Models for urinary $\mathrm{Hg}$ were not estimated for Gorogo, as the urinary $\mathrm{Hg}$ distribution was very narrow (all very low values). Deviations from linear associations between $\mathrm{Hg}$ and $\mathrm{BP}$ were explored using smoothing techniques (lowess) and depicted using quintiles of the $\mathrm{Hg}$ distributions. Small sample sizes limited our ability to perform multilevel models such as linear mixed models despite clustering by household. However, the inferences presented here are likely conservative because the exposures of interest vary across individuals within households [43].

All linear regression models were ran including and excluding outliers with emergency high BP or SG-adjusted urinary $\mathrm{Hg}>45 \mu \mathrm{g} / \mathrm{L}$. Participants excluded for emergency high BP all had SG-adjusted urinary $\mathrm{Hg}$ concentrations below $6.5 \mu \mathrm{g} / \mathrm{L}$. Three Kejetia participants with very high urinary $\mathrm{Hg}$ levels were excluded as outliers (SG-adjusted urinary $\mathrm{Hg}$ was 998.0, 268.4, and 106.5 $\mu \mathrm{g} / \mathrm{L}$ for outliers). Exclusion of outliers (emergency high BP or SG-adjusted urinary $\mathrm{Hg}>45 \mu \mathrm{g} / \mathrm{L}$ ) improved the strength of the associations in linear regressions and are presented here.

\section{Results}

There were 96 participants from 54 households in Kejetia and 75 participants from 26 households in Gorogo. Table 2 outlines the demographics, BMI, and smoking histories of participants, stratified by community and sex. Kejetia participants were younger than Gorogo participants, with $66.7 \%$ in Kejetia under the age of 35 , but only $22.7 \%$ in Gorogo under 35 years. Kejetia participants were predominantly current miners $(72.9 \%)$, but many people engaged in multiple work activities in both communities. The majority of participants in Kejetia and Gorogo had a normal BMI (18.5 to 24.9), but women in Kejetia and Gorogo had a higher prevalence of overweight BMI (25.0 to 29.9). Smoking, while less common, was almost exclusively seen in males and predominantly among miners in Kejetia. Seventeen (17.7\%) of Kejetia participants and 16 (21.3\%) of Gorogo participants had hypertension ( $\mathrm{SBP} \geq 140 \mathrm{mmHg}$ or $\mathrm{DBP} \geq 90 \mathrm{mmHg}$ ) (Table 2). 
Table 2. Demographics and BP of participants in Kejetia and Gorogo, and stratified by mining status.

\begin{tabular}{|c|c|c|c|c|}
\hline & \multicolumn{3}{|c|}{ Kejetia } & \multirow{2}{*}{ Gorogo } \\
\hline & All & Miners $^{a}$ & Non-Miners ${ }^{\text {a }}$ & \\
\hline$n$ participants & 96 & 70 & 26 & 75 \\
\hline$n$ households & 54 & 41 & 18 & 26 \\
\hline$\%$ Male & $49(51.0 \%)$ & $42(60.0 \%)^{* *}$ & $7(26.9 \%)$ & $34(45.3 \%)$ \\
\hline Mean (SD) & $31.4(10.9)^{* * *}$ & $30.6(9.7)$ & $33.8(13.6)$ & $51.5(18.8)$ \\
\hline \multicolumn{5}{|l|}{ BMI $^{b}$} \\
\hline$<18.5$ & $5(5.2 \%)$ & $4(5.7 \%)$ & $1(3.8 \%)$ & $12(16.0 \%)$ \\
\hline 18.5 to 24.9 & $73(76.0 \%)$ & $59(84.3 \%)$ & $14(53.8 \%)$ & $52(69.3 \%)$ \\
\hline 25 to 29.9 & $13(13.5 \%)$ & $5(7.1 \%)$ & $8(30.8 \%)$ & $10(13.3 \%)$ \\
\hline 30 or higher & $5(5.2 \%)$ & $2(2.9 \%)$ & $3(11.5 \%)$ & $1(1.3 \%)$ \\
\hline Mean (SD) & $22.7(3.2)$ & $22.1(2.7)^{* *}$ & $24.5(3.7)$ & $21.8(3.1)$ \\
\hline \multicolumn{5}{|l|}{ Smoking } \\
\hline Current smoker & $15(15.6 \%)$ & $14(20.0 \%)$ & $1(3.8 \%)$ & $14(18.7 \%)$ \\
\hline Ex-smoker & $7(7.3 \%)$ & $6(8.6 \%)$ & $1(3.8 \%)$ & $9(12.0 \%)$ \\
\hline$n$ ever-smokers with pack-years ${ }^{c}$ & 16 & 15 & 1 & 14 \\
\hline Cigarette pack-years ${ }^{c}$ & $15.8(26.6)$ & $15.1(27.4)$ & 25.5 & $3.9(2.1)$ \\
\hline \multicolumn{5}{|l|}{ Blood Pressure $\quad$ Mean (SD) } \\
\hline Systolic BP $(\mathrm{mmHg})$ & $123.5(15.4)$ & $122.6(12.4)$ & $125.8(21.7)$ & $126.1(20.0)$ \\
\hline Diastolic BP (mmHg) & $76.7(11.9)$ & $75.2(10.3)^{*}$ & $80.6(14.9)$ & $75.4(11.5)$ \\
\hline Pulse Pressure ${ }^{\mathrm{d}}(\mathrm{mmHg})$ & $46.9(9.3)^{*}$ & $47.5(8.2)$ & $45.2(11.8)$ & $50.7(13.3)$ \\
\hline Mean Arterial Pressure ${ }^{\mathrm{e}}(\mathrm{mmHg})$ & $92.3(12.4)$ & $91.0(10.4)$ & $95.7(16.5)$ & $92.3(13.4)$ \\
\hline Pulse & $77.1(1.6)^{* * * *}$ & $77.0(1.5)$ & $77.2(1.7)$ & $74.6(3.2)$ \\
\hline \multicolumn{5}{|l|}{ BP Classifications ${ }^{\mathrm{f}}$} \\
\hline Normal & $38(39.6 \%)$ & $27(38.6 \%)$ & $11(42.3 \%)$ & $30(40.0 \%)$ \\
\hline Prehypertension & $41(42.7 \%)$ & $32(45.7 \%)$ & $9(34.6 \%)$ & $29(38.7 \%)$ \\
\hline Apparent hypertension & $17(17.7 \%)$ & $11(15.7 \%)$ & $6(23.1 \%)$ & $16(21.3 \%)$ \\
\hline Hypertension Stage 1 & $12(12.5 \%)$ & $9(12.9 \%)$ & $3(11.5 \%)$ & $8(10.7 \%)$ \\
\hline Hypertension Stage 2 & $5(5.2 \%)$ & $2(2.9 \%)$ & $3(11.5 \%)$ & $8(10.7 \%)$ \\
\hline
\end{tabular}

${ }^{a}$ Refers to current miners and non-current miners; ${ }^{\mathbf{b}}$ For BMI, $\mathrm{n}=74$ for Gorogo; ${ }^{\mathrm{c}}$ Cigarette pack-years only include ever-smokers; ${ }^{\mathrm{d}}$ Pulse pressure $=$ systolic - diastolic BP; ${ }^{\mathrm{e}}$ Mean arterial pressure $=\mathrm{DBP}+0.333^{*}$ pulse pressure [42]; ${ }^{\mathrm{f}}$ Normal BP is SBP < 120 and DBP < 80; prehypertension BP is SBP: $120-139$ or DBP: 80-89; hypertension is $\mathrm{SBP} \geq 140$ or $\mathrm{DBP} \geq 90$; hypertension stage 1 is SBP: $140-159$ or $90-99$; hypertension stage 2 is $\mathrm{SBP} \geq 160$ or DBP $\geq 100$; ${ }^{*}$ Man-Whitney tests comparing Kejetia to Gorogo participants and Kejetia miners to non-miners: ${ }^{*} p<0.05 ;{ }^{* *} p<0.01 ;{ }^{* * *} p<0.001$.

Urinary and hair $\mathrm{Hg}$ biomarkers had skewed distributions. Descriptive statistics are reported in Table 3. In Kejetia the median (interquartile range; IQR) unadjusted urinary $\mathrm{Hg}$ concentration was 2.71 (1.03, 10.9) $\mu \mathrm{g} / \mathrm{L}$ and the median SG-adjusted urinary $\mathrm{Hg}$ was $3.1(1.13,10.1) \mu \mathrm{g} / \mathrm{L}(\mathrm{n}=91)$. The median hair $\mathrm{Hg}$ concentration was $0.782(0.404,1.20) \mu \mathrm{g} / \mathrm{g}(\mathrm{n}=69)$ in Kejetia. Hg concentrations in urine (adjusted and unadjusted) and hair were significantly higher in Kejetia than Gorogo participants and Kejetia miners than non-miners. In Gorogo, urinary $\mathrm{Hg}$ was very low, with a median SG-adjusted $\mathrm{Hg}$ 
concentration of $0.154(0.095,0.261) \mu \mathrm{g} / \mathrm{L}(\mathrm{n}=70)$. Median hair $\mathrm{Hg}$ concentrations in Gorogo were $0.181(0.119,0.244) \mu \mathrm{g} / \mathrm{g}(\mathrm{n}=59)$.

Table 3. Mercury concentrations in urine and hair samples of participants.

\begin{tabular}{|c|c|c|c|c|c|}
\hline & \multicolumn{3}{|c|}{ Kejetia } & \multirow{2}{*}{ Gorogo } \\
\hline & & All & Miners $^{\text {a }}$ & Non-Miners ${ }^{\text {a }}$ & \\
\hline Urine & $n$ & 91 & 67 & 24 & 70 \\
\hline \multicolumn{6}{|c|}{ Urinary Specific Gravity (SG) } \\
\hline & Mean (SD) & $1.018(0.007)^{* * * *}$ & $1.017(0.007)$ & $1.020(0.006)$ & $1.014(0.006)$ \\
\hline \multicolumn{6}{|c|}{ Urinary $\mathrm{Hg}(\mu \mathrm{g} / \mathrm{L})$} \\
\hline & Mean (SD) & $29.4(148.6)^{* * *}$ & $37.6(172.7) *$ & $6.61(13.2)$ & $0.161(0.131)$ \\
\hline & Median & 2.71 & 4.24 & 1.41 & 0.114 \\
\hline & $\mathrm{IQR}^{\mathrm{b}}$ & $1.03,10.9$ & $1.24,11.0$ & $0.742,5.23$ & $0.079,0.217$ \\
\hline & Min-Max & $0.160-1372.3$ & $0.160-1372.3$ & $0.199-58.1$ & $0.026-0.580$ \\
\hline \multicolumn{6}{|c|}{ SG-adj. Urinary $\mathrm{Hg}^{\mathrm{c}}(\mu \mathrm{g} / \mathrm{L})$} \\
\hline & Mean (SD) & $21.7(107.9)^{* * *}$ & $28.0(125.3)^{* * *}$ & $4.22(6.88)$ & $0.216(0.194)$ \\
\hline & Median & 3.10 & 5.17 & 1.18 & 0.154 \\
\hline & $\mathrm{IQR}^{\mathrm{b}}$ & $1.13,10.1$ & $1.90,12.5$ & $0.733,3.61$ & $0.095,0.261$ \\
\hline & Min-Max & $0.188-998.1$ & $0.188-998.1$ & $0.212-25.8$ & $0.042-1.24$ \\
\hline \multirow[t]{5}{*}{ Hair Hg $(\mu \mathrm{g} / \mathrm{g})$} & $n$ & 69 & 50 & 19 & 59 \\
\hline & Mean (SD) & $0.958(0.742)^{* * * *}$ & $1.11(0.807)^{* *}$ & $0.558(0.272)$ & $0.231(0.202)$ \\
\hline & Median & 0.782 & 0.945 & 0.419 & 0.181 \\
\hline & $\mathrm{IQR}^{\mathrm{b}}$ & $0.404,1.20$ & $0.571,1.44$ & $0.329,0.718$ & $0.119,0.244$ \\
\hline & Min-Max & $0.132-3.69$ & $0.132-3.69$ & $0.237-1.10$ & $0.037-1.37$ \\
\hline
\end{tabular}

\footnotetext{
${ }^{a}$ Refers to current miners and non-current miners; ${ }^{b}$ Interquartile range (25th percentile, 75 th percentile);

c Specific gravity adjusted urinary $\mathrm{Hg}$ : Urinary Hg * [(1-avg. SG]/[Urine SG-1]); * Man-Whitney tests comparing Kejetia to Gorogo participants and Kejetia miners to non-miners: ${ }^{*} p<0.05 ;{ }^{* *} p<0.01$; $* * * * 0.001$.
}

In bivariate analyses of $\mathrm{Hg}$ exposure biomarkers, $\mathrm{SG}$-adjusted urinary and hair $\mathrm{Hg}$ were significantly correlated to each other in Kejetia (Spearman's $\rho=0.757, p<0.001)$ and Gorogo $(\rho=0.405, p=0.002)$. As displayed in the scatterplots in Figure 1, there were no significant correlations between SG-adjusted urinary $\mathrm{Hg}$ to SBP, DBP, or MAP in Kejetia or Gorogo. Hair $\mathrm{Hg}$ was not significantly correlated to any $\mathrm{BP}$ or pulse measures in either community. PP was negatively correlated to SG-adjusted urinary $\mathrm{Hg}$ in Gorogo $(\rho=-0.261, p=0.029)$, but not in Kejetia. SG-adjusted urinary Hg was significantly correlated to pulse in Kejetia $(\rho=-0.214, p=0.042)$ and Gorogo $(\rho=-0.323, p=0.006)$. Figure 2 displays the mean SBP and DBP by quintiles of SG-adjusted urinary $\mathrm{Hg}$ in Kejetia. While the SG-urinary $\mathrm{Hg}$ concentrations are not significantly different by quintile group, the graph does indicate that the trend may be non-linear as elemental $\mathrm{Hg}$ exposures increase.

In other bivariate analyses, age was significantly correlated to SBP (Kejetia: Pearson $=0.433$, $p<0.001$; Gorogo: Pearson $=0.346, p=0.002$ ), DBP (Kejetia: Pearson $=0.485, p<0.001$ ), PP (Gorogo: Pearson $=0.358, p=0.002)$, and MAP (Kejetia: Pearson $=0.489, p<0.001$; Gorogo: Pearson $=0.276, p=0.016$ ). BMI and smoking pack-years were not significantly correlated to BP measures. Pack-years was significantly correlated to SG-adjusted urinary $\mathrm{Hg}$ in Kejetia $(\rho=0.220$, $p=0.044)$. 

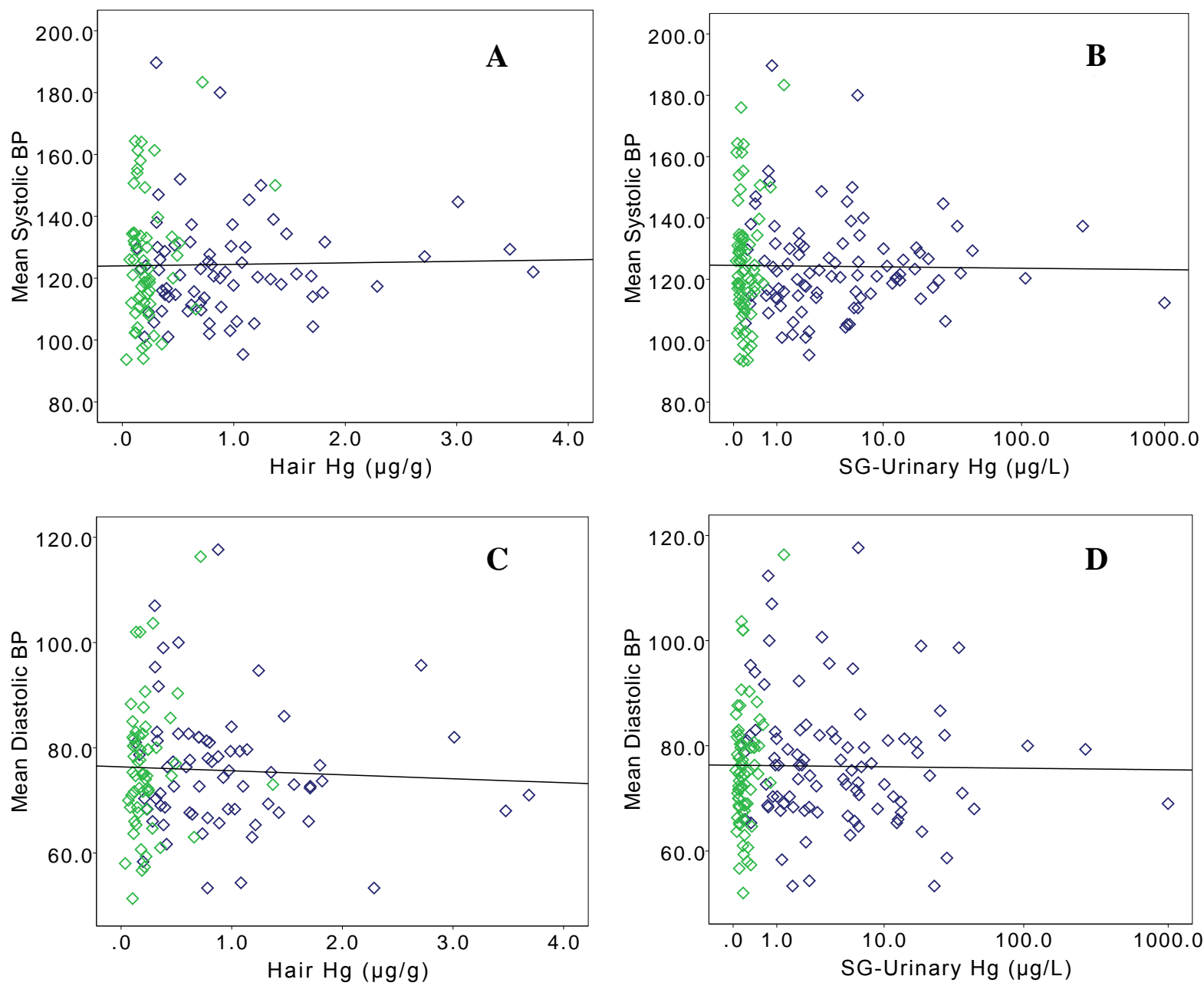

Figure 1. Scatterplots of BP by specific gravity-adjusted urinary $\mathrm{Hg}$ and hair $\mathrm{Hg}$ for Kejetia (dark blue) and Gorogo (green) participants. Systolic BP is represented at top with hair $\mathrm{Hg}(\mathbf{A})$ and SG-adjusted urinary $\mathrm{Hg}(\mathbf{B})$, and diastolic BP is displayed at bottom with hair $\mathrm{Hg}(\mathbf{C})$ and SG-adjusted urinary $\mathrm{Hg}(\mathbf{D})$.

Table 4 displays the results of linear regression models associating hair $\mathrm{Hg}$ levels and BP outcomes, while excluding outliers. Overall, the adjusted $\mathrm{R}^{2}$ values of the model were low (maximum was 0.350) and no significant associations were observed with hair $\mathrm{Hg}$. In Kejetia and Gorogo, the association of hair $\mathrm{Hg}$ on SBP is positive $(\beta=1.45, p=0.41$; and $\beta=0.748, p=0.95$, respectively), and with DBP it is negative ( $\beta=-0.696, p=0.65$; and $\beta=-1.71, p=0.83$, respectively), though none of these are statistically significant. Increasing hair $\mathrm{Hg}$ was associated with an increase in PP in Kejetia and Gorogo ( $\beta=2.09, p=0.15$; and $\beta=2.46, p=0.76$, respectively). MAP did not have a significant association with hair $\mathrm{Hg}$ in Kejetia or Gorogo. The association of pulse and hair $\mathrm{Hg}$ was positive in Gorogo $(\beta=3.22, p=0.13)$, but negative in Kejetia $(\beta=-0.328, p=0.26)$. The relationship with the female sex, current smoking status, and ex-smoking status were largely negative with SBP, DBP, PP, MAP, and pulse in Kejetia and Gorogo, with an exception for pulse with female sex and current smokers in Gorogo, and DBP with ex-smokers in Kejetia and Kejetia miners (all not significant). Models including participants with emergency high BP yielded similar results (data not shown). 
Table 4. Results of linear regression models for BP measures and hair Hg concentrations. Each line represents a separate model. Analyses excluded participants with emergency high BP statuses $(n=4)$. Statistically significant results are in bold font.

\begin{tabular}{|c|c|c|c|c|c|c|c|c|c|}
\hline & \multirow{2}{*}{ Model } & \multirow{2}{*}{$\mathbf{n}$} & \multirow{2}{*}{ Adjusted $r^{2}$} & \multirow{2}{*}{$\frac{\text { Intercept }}{\beta}$} & Hair Hg $(\mu \mathrm{g} / \mathrm{g})$ & Female & Current Smoker & Ex-Smoker & Age (Years) \\
\hline & & & & & \multicolumn{5}{|c|}{$\beta(p$-value $)$} \\
\hline \multirow{2}{*}{ Systolic BP } & Gorogo & 58 & 0.172 & 114.8 & $0.748(0.95)$ & $-13.4(0.07)$ & $-15.7(0.06)$ & $-13.8(0.16)$ & $0.433(0.001)$ \\
\hline & Kejetia: Current miners & 50 & 0.283 & 109.6 & $1.40(0.49)$ & $-11.3(0.005)$ & $-13.3(0.017)$ & $-6.73(0.30)$ & $0.648(<0.001)$ \\
\hline \multirow{2}{*}{ Diastolic BP } & Gorogo & 58 & -0.016 & 71.3 & $-1.71(0.83)$ & $-3.63(0.44)$ & $-3.60(0.49)$ & $-4.47(0.48)$ & $0.150(0.07)$ \\
\hline & Kejetia: Current miners & 50 & 0.285 & 60.0 & $-0.508(0.75)$ & $-3.80(0.21)$ & $-8.23(0.06)$ & $2.44(0.62)$ & $0.601(<0.001)$ \\
\hline \multirow{3}{*}{ Pulse pressure ${ }^{a}$} & Gorogo & 58 & 0.184 & 43.4 & $2.46(0.76)$ & $-9.74(0.049)$ & $-12.1(0.029)$ & $-9.30(0.16)$ & $0.283(0.002)$ \\
\hline & Kejetia & 67 & 0.197 & 50.4 & $2.09(0.15)$ & $-9.45(<0.001)$ & $-5.51(0.16)$ & $-9.64(0.040)$ & $0.030(0.79)$ \\
\hline & Kejetia: Current miners & 50 & 0.101 & 49.6 & $1.91(0.23)$ & $-7.47(0.015)$ & $-5.11(0.23)$ & $-9.17(0.07)$ & $0.047(0.72)$ \\
\hline $\begin{array}{c}\text { Mean arterial } \\
\text { pressure }^{\mathrm{b}}\end{array}$ & Gorogo & 58 & 0.076 & 85.8 & $-0.890(0.92)$ & $-6.85(0.19)$ & $-7.61(0.19)$ & $-7.55(0.28)$ & $0.245(0.009)$ \\
\hline \multirow[t]{2}{*}{ Pulse } & Kejetia & 67 & 0.066 & 79.4 & $-0.328(0.26)$ & $-0.874(0.09)$ & $-0.102(0.90)$ & $-1.72(0.07)$ & $-0.048(0.038)$ \\
\hline & Kejetia: Current miners & 50 & -0.015 & 78.6 & $-0.333(0.29)$ & $-0.571(0.34)$ & $-0.114(0.89)$ & $-1.57(0.12)$ & $-0.026(0.33)$ \\
\hline
\end{tabular}

${ }^{\text {a }}$ Pulse pressure is SBP - DBP; ${ }^{b}$ Mean arterial pressure $=$ DBP $+0.333^{*}$ pulse pressure [42]. 


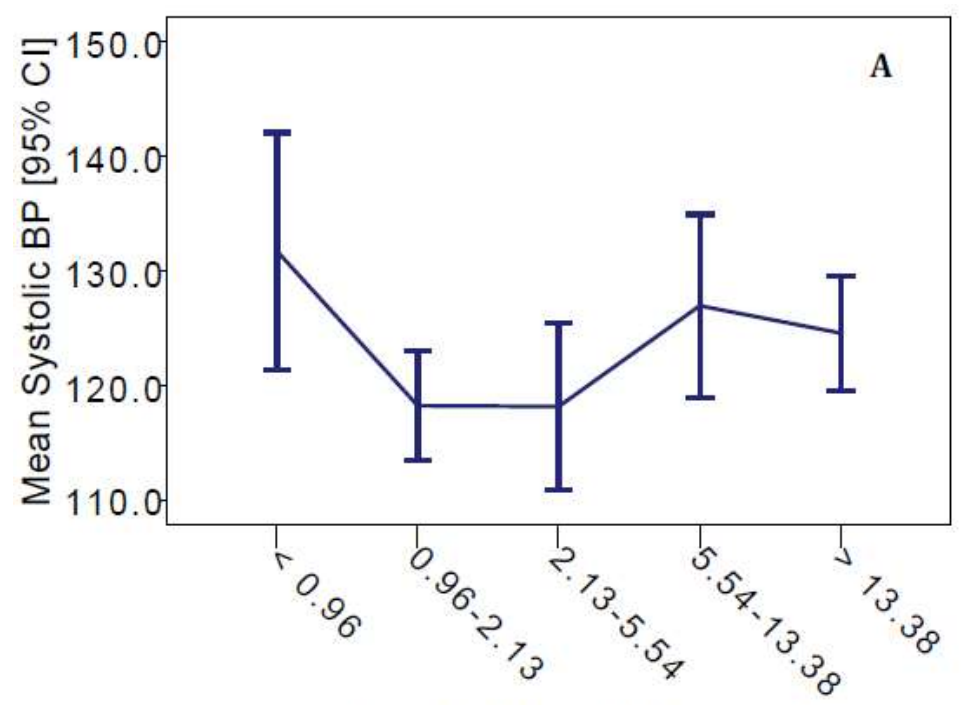

SG-Urinary $\mathrm{Hg}$ quintiles $(\mu \mathrm{g} / \mathrm{L})$

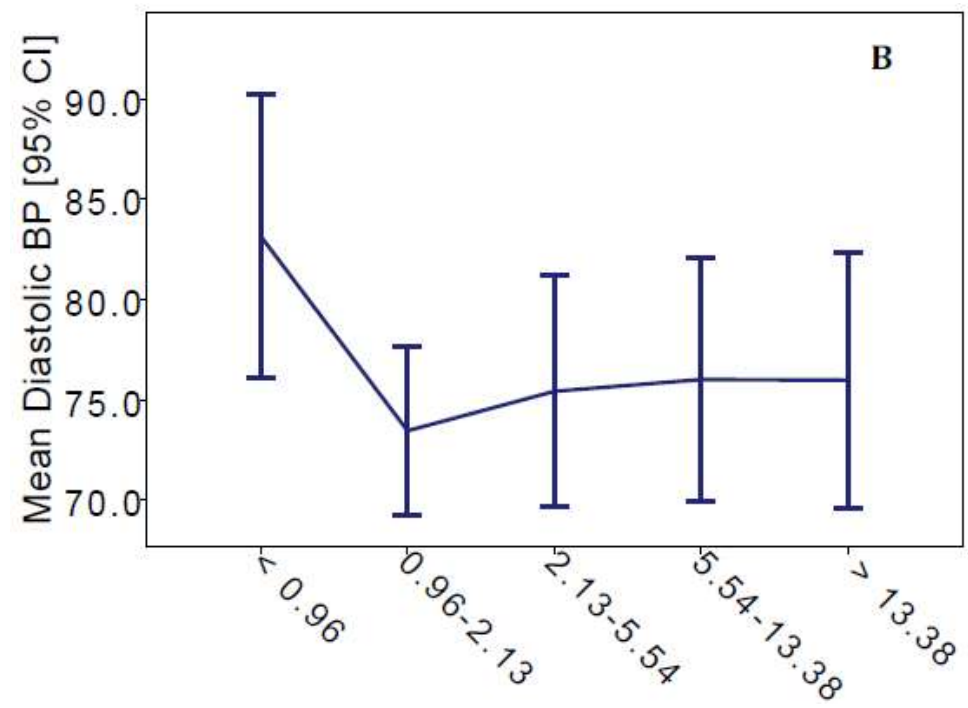

Figure 2. Mean systolic (A) and diastolic BP (B) by quintiles of SG-adjusted urinary $\mathrm{Hg}$ concentrations in Kejetia. Error bars represent $95 \%$ confidence intervals.

Analyses with SG-adjusted urinary Hg (Table 5) show no significant association with SBP, DBP, PP, MAP, or pulse. For Kejetia current miners, the association between SG-adjusted urinary Hg and PP was approaching significance $(\beta=0.205, p=0.07)$. SBP had a positive association with SG-urinary $\mathrm{Hg}$ and DBP and pulse had a negative association with SG-urinary $\mathrm{Hg}$, albeit non-significant. Female sex and ex-smoking status were associated with lower SBP, DBP, PP, MAP, and pulse. Current smoking status was associated with lower SBP, DBP, PP, and MAP, but higher pulse (all not significant). Models including unadjusted urinary $\mathrm{Hg}$, participants with emergency high $\mathrm{BP}$, or SG-adjusted urinary $\mathrm{Hg}$ concentrations $>45 \mu \mathrm{g} / \mathrm{L}$ were similar or had wider confidence intervals, with no significant associations with urinary $\mathrm{Hg}$ and $\mathrm{BP}$ outcomes (data not shown). 
Table 5. Results of linear regression models for BP measures and specific gravity-adjusted urinary Hg concentrations. Each line represents a separate model. Analyses excluded participants with emergency high BP statuses $(\mathrm{n}=4)$ and urinary $\mathrm{Hg}$ concentrations $<45 \mu \mathrm{g} / \mathrm{L}(\mathrm{n}=3)$. Statistically significant results are in bold font.

\begin{tabular}{|c|c|c|c|c|c|c|c|c|c|}
\hline & \multirow{2}{*}{ Model } & \multirow{2}{*}{$\mathbf{n}$} & \multirow{2}{*}{ Adjusted $r^{2}$} & \multirow{2}{*}{$\frac{\text { Intercept }}{\beta}$} & SG-Urinary Hg $(\mu \mathrm{g} / \mathrm{L})$ & Female & Current Smoker & Ex-Smoker & Age (Years) \\
\hline & & & & & \multicolumn{5}{|c|}{$\beta(p$-value $)$} \\
\hline \multirow{2}{*}{ Systolic BP } & Kejetia & 86 & 0.216 & 114.6 & $0.010(0.94)$ & $-10.6(0.001)$ & $-5.28(0.19)$ & $-10.0(0.046)$ & $0.466(<0.001)$ \\
\hline & Kejetia: Current miners & 64 & 0.244 & 108.3 & $0.098(0.52)$ & $-9.35(0.009)$ & $-5.73(0.18)$ & $-8.63(0.11)$ & $0.622(<0.001)$ \\
\hline \multirow{2}{*}{ Diastolic BP } & Kejetia & 86 & 0.279 & 62.1 & $-0.087(0.46)$ & $-4.31(0.09)$ & $-1.07(0.75)$ & $-3.03(0.46)$ & $0.533(<0.001)$ \\
\hline & Kejetia: Current miners & 64 & 0.303 & 59.1 & $-0.106(0.40)$ & $-3.77(0.19)$ & $-0.263(0.94)$ & $-1.44(0.74)$ & $0.595(<0.001)$ \\
\hline \multirow{2}{*}{ Pulse pressure ${ }^{a}$} & Kejetia & 85 & 0.109 & 50.6 & $0.116(0.25)$ & $-6.85(0.002)$ & $-4.77(0.10)$ & $-7.30(0.041)$ & $-0.006(0.95)$ \\
\hline & Kejetia: Current miners & 64 & 0.112 & 49.2 & $0.205(0.07)$ & $-5.57(0.028)$ & $-5.47(0.07)$ & $-7.19(0.06)$ & $0.026(0.81)$ \\
\hline \multirow{2}{*}{$\begin{array}{c}\text { Mean arterial } \\
\text { pressure }^{\mathrm{b}}\end{array}$} & Kejetia & 85 & 0.266 & 80.6 & $-0.046(0.68)$ & $-6.82(0.006)$ & $-2.13(0.50)$ & $-5.11(0.20)$ & $0.473(<0.001)$ \\
\hline & Kejetia: Current miners & 64 & 0.302 & 75.5 & $-0.038(0.76)$ & $-5.64(0.05)$ & $-2.08(0.55)$ & $-3.83(0.38)$ & $0.604(<0.001)$ \\
\hline \multirow{2}{*}{ Pulse } & Kejetia & 85 & 0.055 & 78.6 & $-0.029(0.15)$ & $-0.766(0.08)$ & $0.003(0.995)$ & $-1.36(0.05)$ & $-0.028(0.10)$ \\
\hline & Kejetia: Current miners & 64 & 0.005 & 77.9 & $-0.016(0.47)$ & $-0.254(0.61)$ & $0.176(0.77)$ & $-1.39(0.07)$ & $-0.019(0.40)$ \\
\hline
\end{tabular}

${ }^{a}$ Pulse pressure is SBP - DBP; ${ }^{b}$ Mean arterial pressure $=\mathrm{DBP}+0.333^{*}$ pulse pressure [42]. 


\section{Discussion}

There is increasing concern about the cardiovascular effects of mercury $(\mathrm{Hg})$ exposure, and that organic $\mathrm{MeHg}$ and inorganic $\mathrm{Hg}^{2+}$ may affect the cardiovascular system and BP differentially. In small-scale gold mining communities, inorganic, elemental $\mathrm{Hg}$ exposures are high for community members and miners. Little is known about the Hg-associated effects on BP in such groups, and the high exposures may represent a unique opportunity to increase understanding of $\mathrm{Hg}$-associated cardiovascular risk. Here we conducted a cross-sectional epidemiological study to assess the relationships between exposures to both $\mathrm{MeHg}$ and inorganic $\mathrm{Hg}$ with $\mathrm{BP}$. As with past studies from this region [32], exposures to $\mathrm{MeHg}$ were relatively low whereas exposures to inorganic $\mathrm{Hg}$ were high. When the exposure data were associated with BP measures, though relationships were in the expected direction based on past studies, they were not of statistical significance. We are limited in particular by a small number of participants with elevated urinary and hair $\mathrm{Hg}$ concentrations and a small sample size overall.

In the current study, the relationship between hair $\mathrm{Hg}$ and SBP or DBP was not significant. The overall lack of significant finding here is perhaps due to lower hair Hg levels (i.e., IQR of 0.4 to $0.8 \mu \mathrm{g} / \mathrm{g}$ ) in our study than these other studies. Fish $\mathrm{Hg}$ concentrations were low in the area surrounding Kejetia and across Ghana [37,44]. Fish consumption was also low in the Kejetia area of the Talensi District [32]. Omega-3 fatty acids present in fish may reduce hypertension and coronary heart disease [14,45], and this effect may be more pronounced at higher selenium and lower Hg levels [45]. The low consumption of fish, low $\mathrm{Hg}$ levels in fish, and potential benefits of omega-3 fatty acids in fish may all influence BP in this study. Hair samples from ASG miners or community residents may also overestimate $\mathrm{MeHg}$ exposure, thus clouding any association. Sherman et al. [46] found that hair $\mathrm{Hg}$ from a subsample of our Kejetia miners collected in 2011 and other Kejetia miners sampled in 2010 had a low percentage of $\mathrm{MeHg}$ as total $\mathrm{Hg}$ (7.6\%-29\%), suggesting that the majority of the total $\mathrm{Hg}$ is exogenously adsorbed elemental $\mathrm{Hg}$.

The study observed a non-significant positive association with SBP and hair $\mathrm{Hg}$, which has been observed in other studies of hair of blood $\mathrm{Hg}$, both usual measures of MeHg [13-16,25]. For DBP, our study found a non-significant negative association between elevated hair $\mathrm{Hg}$ and $\mathrm{DBP}$, in contrast to other research, which have all observed an exposure-associated increase in DBP [13-16,20,25]. Goodrich et al. [16] estimated a $2.76 \mathrm{mmHg}$ increase in DBP for every $1 \mu \mathrm{g} / \mathrm{g}$ increase in hair $\mathrm{Hg}$.

For exposures to inorganic $\mathrm{Hg}$, the levels reported here were high as expected for current miners. The median value $(4.24 \mu \mathrm{g} / \mathrm{L})$ was similar to our past work with miners in this same community $(3.6 \mu \mathrm{g} / \mathrm{L})$ [32] as well as values found in other ASGM communities [47]. These exposure values are much greater than values from other studies in which $\mathrm{Hg}$-associated decreases in SBP have been reported. For example, Park et al.'s [20] study of healthy U.S. adults had a 95\% confidence limit of $0.47-0.54 \mu \mathrm{g} / \mathrm{L}$ urinary $\mathrm{Hg}$ and Goodrich et al. [16] measured urinary $\mathrm{Hg}$ concentrations ranging from 0.03 to $5.54 \mu \mathrm{g} / \mathrm{L} \mathrm{Hg}$ (median: $0.63 \mu \mathrm{g} / \mathrm{L}$ ). Non-miners have significantly lower urinary $\mathrm{Hg}$ exposures, but also significantly higher BMIs than miners in Kejetia. This could explain a higher susceptibility to hypertension if non-miners have other lifestyle factors (e.g., diet, how sedentary) in addition to BMI [48].

Three studies of U.S. adults observed significant decreases in SBP [16,20,21] and one observed a significant decrease in DBP with urinary $\mathrm{Hg}$ (Table 1) [21]. Park et al. [20] estimated a $0.114 \mathrm{mmHg}$ 
decrease in SBP with a $10 \%$ increase in urinary $\mathrm{Hg}$ and Goodrich et al. [16] estimated a $1.80 \mathrm{mmHg}$ decrease in SBP with every $1 \mu \mathrm{g} / \mathrm{L}$ increase in urinary $\mathrm{Hg}$. While these studies help contextualize our study, the average urinary $\mathrm{Hg}$ concentrations were far lower than in our Kejetia participants. One study of Slovenian $\mathrm{Hg}$ miners $(\mathrm{n}=54)$ with elevated historic $\mathrm{Hg}$ exposures observed significant increases in SBP and DBP, but had an average annual past exposure of $69.3 \mu \mathrm{g} / \mathrm{L} \mathrm{Hg}$ and a current measure of $2.5 \mu \mathrm{g} / \mathrm{L} \mathrm{Hg}$ in their urine [22].

Given this research and our lack of significant results, it is possible that inorganic $\mathrm{Hg}$-associated impacts on BP may vary depending on the level of elemental $\mathrm{Hg}$ exposure. As observed in studies with lower urinary $\mathrm{Hg}$ concentrations, there may be a negative association at lower elemental $\mathrm{Hg}$ exposure, but a positive association at higher exposures. With only three participants with $>70 \mu \mathrm{g} / \mathrm{L}$ urinary $\mathrm{Hg}$ in Kejetia, we do not have similar exposures as observed in Kobal et al.'s study of Slovenian $\mathrm{Hg}$ miners [22], and may not be able to elucidate this relationship. The impact on BP may be more deleterious for miners with higher exposures to elemental $\mathrm{Hg}$.

Hair and urinary $\mathrm{Hg}$ had positive associations with $\mathrm{PP}$, but were not statistically significant. Other studies observed that blood $\mathrm{Hg}$ was positively associated with increasing PP [15,49,50]. The association of urinary $\mathrm{Hg}$ levels on $\mathrm{PP}$ has not been explored previously. Elevated PP is recognized as a risk factor for cardiovascular disease [51]. In one study, participants with higher PP had increased SBP and decreased DBP compared to participants with lower PP [9]. MAP, which is associated with the development of cardiovascular disease later in life among young men [52], is also not significantly associated with BP measures. Studies have observed decreased heart rate variability with blood $\mathrm{Hg}[49,53,54]$. The negative association for pulse with urinary and hair $\mathrm{Hg}$ may be more pronounced in Kejetia, where $\mathrm{Hg}$ exposures are higher.

While we did not see a significant relationship with hair or urinary $\mathrm{Hg}$ and $\mathrm{BP}$, our work generally follows the trends seen in the literature. Our study was limited by a small sample size, particularly of participants with urinary $\mathrm{Hg}$ greater than $50 \mu \mathrm{g} / \mathrm{L}$, though it should be mentioned that the average urinary $\mathrm{Hg}$ value in other population surveys is usually $<5 \mu \mathrm{g} / \mathrm{L} \mathrm{Hg}$. Kejetia and Gorogo vary greatly in demographics, as Kejetia is a younger and more transient community. This plays an important role, as age is associated with an increase in BP, but running stratified models by community helped to account for these differences. Hypertension is rising in Ghana as it becomes more industrialized [30], underscoring the value in understanding the relationship of $\mathrm{Hg}$ to $\mathrm{BP}$ and cardiovascular health, particularly for the over 500,000 people employed in ASGM [55].

\section{Conclusions}

Mercury is a known toxicant that many ASGM miners are exposed to at elevated levels, but no studies have examined the relationship between $\mathrm{Hg}$ and BP in these populations. While we did not see a significant relationship between hair or urinary $\mathrm{Hg}$ and $\mathrm{BP}$, our research emphasizes the need for further studies to examine a larger population with $>10 \mu \mathrm{g} / \mathrm{L}$ urinary $\mathrm{Hg}$ to help clarify the relationship of elemental $\mathrm{Hg}$ with $\mathrm{BP}$. 


\section{Acknowledgments}

We are grateful for the support and funding from the University of Michigan's Graham Sustainability Institute. This research was also funded by the Minorities Health and Health Disparities Research Training (MHIRT) Program (T37 MD001425-15), National Institute of Health, and administered through the University of Michigan's Center for Human Growth and Development. We would like to thank all researchers, translators, and participants for their work, particularly, Ephraim Sowah Komey, Charles Sampana, Emmanuel Adongo, Rachel Long, Allison Yee, Jing Kaylee Lu, and Codi Sharp.

\section{Author Contributions}

Mozhgon Rajaee wrote the paper with guidance and contributions from Niladri Basu, Brisa Sánchez, and Elisha Renne.

\section{Conflicts of Interest}

The authors declare no conflict of interest.

\section{References}

1. Clarkson, T.W.; Magos, L. The toxicology of mercury and its chemical compounds. Crit. Rev. Toxicol. 2006, 36, 609-662.

2. Karagas, M.R.; Choi, A.L.; Oken, E.; Horvat, M.; Schoeny, R.; Kamai, E.; Cowell, W.; Grandjean, P.; Korrick, S. Evidence on the human health effects of low-level methylmercury exposure. Environ. Health Perspect. 2012, 120, 799-806.

3. Houston, M.C. Role of mercury toxicity in hypertension, cardiovascular disease, and stroke. J. Clin. Hypertens. 2011, 13, 621-627.

4. Wiggers, G.A.; Peçanha, F.M.; Briones, A.M.; Pérez-Girón, J.V.; Miguel, M.; Vassallo, D.V.; Cachofeiro, V.; Alonso, M.J.; Salaices, M. Low mercury concentrations cause oxidative stress and endothelial dysfunction in conductance and resistance arteries. Am. J. Physiol. Heart Circ. Physiol. 2008, 295, H1033-H1043.

5. Salonen, J.T.; Seppänen, K.; Nyyssönen, K.; Korpela, H.; Kauhanen, J.; Kantola, M.; Tuomilehto, J.; Esterbauer, H.; Tatzber, F.; Salonen, R. Intake of mercury from fish, lipid peroxidation, and the risk of myocardial infarction and coronary, cardiovascular, and any death in eastern Finnish men. Circulation 1995, 91, 645-655.

6. Félétou, M.; Vanhoutte, P.M. Endothelial dysfunction: A multifaceted disorder. Am. J. Physiol. Heart Circ. Physiol. 2006, 291, H985-H1002.

7. Touyz, R.M. Reactive oxygen species, vascular oxidative stress, and redox signaling in hypertension: What is the clinical significance? Hypertension 2004, 44, 248-252.

8. Ryan, S.M.; Waack, B.J.; Weno, B.L.; Heistad, D.D. Increases in pulse pressure impair acetylcholine-induced vascular relaxation. Am. Physiol. Soc. 1995, 268, 359-363. 
9. Ceravolo, R.; Maio, R.; Pujia, A.; Sciacqua, A.; Ventura, G.; Costa, M.C.; Sesti, G.; Perticone, F. Pulse pressure and endothelial dysfunction in never-treated hypertensive patients. J. Am. Coll. Cardiol. 2003, 41, 1753-1758.

10. Rhee, H.M.; Choi, B.H. Hemodynamic and electrophysiological effects of mercury in intact anesthetized rabbits and in isolated perfused hearts. Exp. Mol. Pathol. 1989, 50, 281-290.

11. Norn, S.; Permin, H.; Kruse, E.; Kruse, P.R. Mercury-A major agent in the history of medicine and alchemy. Med. Hist. 2008, 36, 21-40.

12. U.S. Environmental Protection Agency (EPA). Mercury Study Report to Congress: Health Effects of Mercury and Mercury Compounds, Volume 5; EPA: Washington, DC, USA, 1997.

13. Choi, A.L.; Weihe, P.; Budtz-jørgensen, E.; Jørgensen, P.J.; Jukka, T.; Tuomainen, T.; Murata, K.; Nielsen, H.P.; Skaalum, M.; Askham, J.; et al. Methylmercury Exposure in Faroese Whaling Men and Adverse Cardiovascular Effects. Environ. Health Perspect. 2009, 117, 367-372.

14. Fillion, M.; Mergler, D.; Passos, C.J.S.; Larribe, F.; Lemire, M.; Guimaraes, J.R.D. A preliminary study of mercury exposure and blood pressure in the Brazilian Amazon. Environ. Health A Glob. Access Sci. Source 2006, 5, 1-9.

15. Valera, B.; Dewailly, É.; Poirier, P. Environmental mercury exposure and blood pressure among Nunavik inuit adults. Hypertension 2009, 54, 981-986.

16. Goodrich, J.M.; Wang, Y.; Gillespie, B.; Werner, R.; Franzblau, A.; Basu, N. Methylmercury and elemental mercury differentially associate with blood pressure among dental professionals. Int. J. Hyg. Environ. Health 2012, 216, 195-201.

17. Bluhm, R.E.; Bobbitt, R.G.; Welch, L.W.; Wood, A.J.J.; Bonfiglio, J.F.; Sarzen, C.; Heath, A.J.; Branch, R.A. Elemental Mercury Vapour Toxicity, Treatment, and Prognosis After Acute, Intensive Exposure in Chloralkali Plant Workers. Part I: History, Neuropsychological Findings and Chelator effects. Hum. Exp. Toxicol. 1992, 11, 201-210.

18. Massaroni, L.; Rossoni, L.V.; Amaral, S.M.; Stefanon, I.; Oliveira, E.M.; Vassallo, D.V. Haemodynamic and electrophysiological acute toxic effects of mercury in anaesthetized rats and in langendorff perfused rat hearts. Pharmacol. Res. 1995, 32, 27-36.

19. Rossoni, L.V.; Amaral, S.M.; Vassallo, P.F.; França, A.; Oliveira, E.M.; Varner, K.J.; Mill, J.G.; Vassallo, D.V. Effects of mercury on the arterial blood pressure of anesthetized rats. Braz. J. Med. Biol. Res. 1999, 32, 989-997.

20. Park, S.K.; Lee, S.; Basu, N.; Franzblau, A. Associations of blood and urinary mercury with hypertension in U.S. Adults: The NHANES 2003-2006. Environ. Res. 2013, 123, 25-32.

21. Siblerud, R.L. The relationship between mercury from dental amalgam and the cardiovascular system. Sci. Total Environ. 1990, 99, 23-35.

22. Kobal, A.B.; Horvat, M.; Prezelj, M.; Briški, A.S.; Krsnik, M.; Dizdarevič, T.; Mazej, D.; Falnoga, I.; Stibilj, V.; Arnerič, N.; et al. The impact of long-term past exposure to elemental mercury on antioxidative capacity and lipid peroxidation in mercury miners. J. Trace Elem. Med. Biol. 2004, 17, 261-274.

23. Center for Disease Control (CDC). Fourth National Report on Human Exposure to Environmental Chemicals; CDC: Atlanta, GA, USA, 2009.

24. Nicolae, A.; Ames, H.; Quiñonez, C. Dental amalgam and urinary mercury concentrations: A descriptive study. BMC Oral Health 2013, 13, 1-12. 
25. Dórea, J.G.; De Souza, J.R.; Rodrigues, P.; Ferrari, Í.; Barbosa, A.C. Hair mercury (signature of fish consumption) and cardiovascular risk in Munduruku and Kayabi Indians of Amazonia. Environ. Res. 2005, 97, 209-219.

26. United Nations Environment Programme (UNEP). Global Mercury Assessment 2013: Sources, Emissions, Releases and Environmental Transport; UNEP: Geneva, Switzerland, 2013.

27. Basu, N.; Clarke, E.; Green, A.; Long, R.; Calys-Tagoe, B.; Chan, L.H.M.; Dzodzomenyo, M.; Fobil, J.N.; Neitzel, R.L.; Obiri, S.; Odei, E.; et al. Integrated Assessment of Artisanal and Small-Scale Gold Mining in Ghana—Part 1: Human Health Review. Int. J. Environ. Res. Public Health 2015, 12, 5143-5176.

28. Wranová, K.; Čejchanová, M.; Spěváčková, V.; Korunová, V.; Vobecký, M.; Spěváček, V. Mercury and methylmercury in hair of selected groups of Czech population. Cent. Eur. J. Public Health 2008, 17, 36-40.

29. Barbosa, A.C.; Boischio, A.A.; East, G.A.; Ferrari, I.; Gonçalves, A.; Silva, P.R.M.; da Cruz, T.M.E. Mercury contamination in the Brazilian Amazon. Environmental and occupational aspects. Water Air Soil Pollut. 1995, 80, 109-121.

30. Bosu, W.K. Epidemic of hypertension in Ghana: A systematic review. BMC Public Health 2010, doi:10.1186/1471-2458-10-418.

31. Pobee, J.O.; Larbi, E.B.; Belcher, D.W.; Wurapa, F.K.; Dodu, S.R. Blood pressure distribution in a rural Ghanaian population. Trans. R. Soc. Trop. Med. Hyg. 1977, 71, 66-72.

32. Paruchuri, Y.; Siuniak, A.; Johnson, N.; Levin, E.; Mitchell, K.; Goodrich, J.M.; Renne, E.P.; Basu, N. Occupational and environmental mercury exposure among small-scale gold miners in the Talensi-Nabdam District of Ghana's Upper East region. Sci. Total Environ. 2010, 408, 6079-6085.

33. Ghana Statistical Service (GSS); Ghana Health Service (GHS); ICF Macro. Ghana Demographic and Health Survey 2008; GSS: Accra, Ghana; GHS: Accra, Ghana; Calverton, MD, USA, 2009.

34. Ferris, B.G. Epidemiology Standardization Project. Am. Thorac. Soc. 1978, 118, 1-120.

35. Hoshaw-Woodard, S. Description and Comparison of the Methods of Cluster Sampling and Lot Quality Assurance Sampling to Assess Immunization Coverage; World Health Organization: Geneva, Switzerland, 2001.

36. U.S. Environmental Protection Agency (EPA) Mercury in Solids and Solutions by Thermal Decomposition, Amalgamation, and Atomic Absorption Spectrophotometry; EPA: Washington, DC, USA, 2007.

37. Rajaee, M.; Long, R.N.; Renne, E.P.; Basu, N. Mercury concentrations and spatial distribution in a Ghanaian small-scale gold mining community. In preparation. 2015.

38. Lee, E.; Park, H.K.; Kim, H.J. Adjustment of urinary mercury in health risk assessment of mercury. J. Korea Med. Sci. 1996, 11, 319-325.

39. Voinescu, G.C.; Shoemaker, M.; Moore, H.; Khanna, R.; Nolph, K.D. The relationship between urine osmolality and specific gravity. Am. J. Med. Sci. 2002, 323, 39-42.

40. Understanding Blood Pressure Readings. Available online: http://www.heart.org/HEARTORG/ Conditions/HighBloodPressure/AboutHighBloodPressure/Understanding-Blood-Pressure-Readings_ UCM_301764_Article.jsp (accessed on 10 January 2015).

41. Pickering, T.G.; Hall, J.E.; Appel, L.J.; Falkner, B.E.; Graves, J.; Hill, M.N.; Jones, D.W.; Kurtz, T.; Sheps, S.G.; Roccella, E.J. Recommendations for blood pressure measurement in 
humans and experimental animals. Part 1: Blood pressure measurement in humans: A statement for professionals from the subcommittee of professional and public education of the American Heart Association cou. Hypertension 2005, 45, 142-161.

42. Razminia, M.; Trivedi, A.; Molnar, J.; Elbzour, M.; Guerrero, M.; Salem, Y.; Ahmed, A.; Khosla, S.; Lubell, D.L. Validation of a new formula for mean arterial pressure calculation: The new formula Is superior to the standard formula. Catheter. Cardiovasc. Interv. 2004, 63, 419-425.

43. Fitzmaurice, G.; Laird, N.; Ware, J. Applied Longitudinal Analysis, 2nd ed.; Wiley: Hoboken, NJ, USA, 2011.

44. Rajaee, M.; Obiri, S.; Green, A.; Long, R.; Cobbina, S.; Nartey, V.; Buck, D.; Antwi, E.; Basu, N. Integrated Assessment of Artisanal and Small-Scale Gold Mining in Ghana-Part 2: Natural Sciences Review. Int. J. Environ. Resesearch Public Health 2015, 12, 8971-9011.

45. Xun, P.; Hou, N.; Daviglus, M.; Liu, K.; Morris, J.S.; Shikany, J.M.; Sidney, S.; Jacobs, D.R.; $\mathrm{He}, \mathrm{K}$. Fish oil, selenium and mercury in relation to incidence of hypertension: A 20-year follow-up study. J. Intern. Med. 2011, 270, 175-186.

46. Sherman, L.S.; Blum, J.D.; Basu, N.; Rajaee, M.; Evers, D.C.; Buck, D.G.; Petrlik, J.; Digangi, J. Assessment of mercury exposure among small-scale gold miners using mercury stable isotopes. Environ. Res. 2015, 137, 226-234.

47. Gibb, H.; O'Leary, K.G. Mercury Exposure and Health Impacts among Individuals in the Artisanal and Small-Scale Gold Mining Community: A Comprehensive Review. Environ. Health Perspect. 2014, 122, 667-672.

48. Hajjar, I.; Kotchen, J.M.; Kotchen, T.A. Hypertension: trends in prevalence, incidence, and control. Annu. Rev. Public Health 2006, 27, 465-490.

49. Valera, B.; Dewailly, E.; Poirier, P. Cardiac autonomic activity and blood pressure among Nunavik Inuit adults exposed to environmental mercury: A cross-sectional study. Environ. Health 2008, doi:10.1186/1476-069X-7-29.

50. Pedersen, E.B.; Jørgensen, M.E.; Pedersen, M.B.; Siggaard, C.; Sørensen, T.B.; Mulvad, G.; Hansen, J.C.; Asmund, G.; Skjoldborg, H. Relationship between mercury in blood and 24-h ambulatory blood pressure in greenlanders and Danes. Am. J. Hypertens. 2005, 18, 612-618.

51. Dart, A.M.; Kingwell, B.A. Pulse pressure-A review of mechanisms and clinical relevance. J. Am. Coll. Cardiol. 2001, 37, 975-984.

52. Sesso, H.D.; Stampfer, M.J.; Rosner, B.; Hennekens, C.H.; Gaziano, J.M.; Manson, J.E.; Glynn, R.J. Systolic and diastolic blood pressure, pulse pressure, and mean arterial pressure as predictors of cardiovascular disease risk in men. Hypertension 2000, 36, 801-807.

53. Valera, B.; Dewailly, E.; Poirier, P.; Counil, E.; Suhas, E. Influence of mercury exposure on blood pressure, resting heart rate and heart rate variability in French Polynesians: A cross-sectional study. Environ. Health 2011, doi:10.1186/1476-069X-10-99.

54. Valera, B.; Muckle, G.; Poirier, P.; Jacobson, S.W.; Jacobson, J.L.; Dewailly, E. Cardiac autonomic activity and blood pressure among Inuit children exposed to mercury. Neurotoxicology 2012, 33, 1067-1074. 
55. Bawa, I. A viewpoint on small-scale gold mining in Ghana: A regulatory perspective on current practices, mercury use and the UNIDO and EU projects. Int. J. Environ. Pollut. 2010, 41, 195-201.

(C) 2015 by the authors; licensee MDPI, Basel, Switzerland. This article is an open access article distributed under the terms and conditions of the Creative Commons Attribution license (http://creativecommons.org/licenses/by/4.0/). 